\title{
LA CULTURA: ¿LITURGIA O AKELARRE?
}

\author{
Gabriel Insausti
}

Universidad de Navarra

\begin{abstract}
Resumen: la cultura contemporánea abunda en expresiones sacrílegas, blasfemas o simplemente repugnantes, que persiguen deliberadamente suscitar un equívoco repudio en el espectador; a menudo sus celebraciones consisten en un aquelarre, una celebración o exaltación del mal que aparece como inversión de la liturgia religiosa, hasta el extremo de que el productor o consumidor de cultura judeocristiano puede llegar a sentir que se enfrenta a una disyuntiva: participar de la cultura de su tiempo o participar de su religión.
\end{abstract}

Palabras clave: arte abyecto, sacrificio, cultura moderna, satanismo.

\section{Culture: Liturgy or "akelarre"?}

Abstract: contemporary culture abounds in sacrilegious, blasphemous or merely disgusting expressions, which chase to arise in the spectator an ambiguous rejection; very often its setup and enactment parallel a sort of black mass, a celebration or appraisal of evil as a result of an inversion of orthodox religious liturgy, so much that the jewish or christian producer/consumer of culture can feel as if confronted by a dilemma: quit his religion and take part of that culture or stick to it and give culture up.

Keywords: Abject Art, Sacrifice, Modern Culture, Satanism.

Recibido: 21/3/2017 Aceptado: 10/6/2017

Me propongo en estas páginas comentar un aspecto del libro de Fernando Inciarte Cultura y verdad: la posible incompatibilidad de la condición de cris- 
tiano con la de artista que percibe el héroe de su primer ensayo, "Qué y cómo", desde la primera página. Es decir, que me propongo no tanto responder a la pregunta por la compatibilidad entre cristianismo y cultura en abstracto sino entre cristianismo y cultura moderna en concreto. Con una advertencia: que pese a admitir de buen grado las definiciones mas maximalistas de "cultura" — “interpretación de la naturaleza", "conjunto de soluciones para la existencia,", etc.- trataré específicamente de los fenómenos culturales más sofisticados. Es decir, de lo que llamamos arte y, en especial, de las artes plásticas, el cine y la literatura.Comenzaré por una imagen de hace pocos años. En ella aparecen tres hombres de rasgos orientales desnudos, sentados a una misma mesa, que armados de cuchillo y tenedor acometen un escalofriante almuerzo: un feto humano. Se trata de una fotografía que documenta una performance realizada por el sedicente artista chino Zhu Yu bajo el lema "No hay límites" y, aunque prohibida en China, o quizá precisamente por estarlo, obtuvo gran éxito a lo largo y ancho del globo. Y de la naturaleza crudamente literal y provocativa de su intervención dejó testimonios sobrados. "Sé que hay quien no cree que el bebé sea real pero lo es", declaró repetidamente, "me lo llevé de un centro médico".

Conocí la imagen en cuestión hacia el año 2007, cuando una amiga mía que dirigía una galería de arte tuvo que preparar un catálogo para una exposición; mi amiga estaba a la sazón embarazada y la imagen le provocó unas molestias pesadillas. Es decir, que probablemente logró su propósito. Eso, entre otras cosas, pretenden el arte abyecto y otras muchas manifestaciones artísticas contemporáneas: captar nuestra atención, alojarse en algún rincón de nuestra memoria. $\mathrm{Y}$, por razones históricas que no tengo tiempo de des- 
arrollar aquí - la puesta bajo sospecha de la belleza como producto burgués; el destierro de toda jouissance en la experiencia estética; la reducción del fenómeno artístico a un proceso semiótico; la avalancha icónica que se cierne sobre el espectador cotidianamente, en una versión abrumadora del mal de Stendhal一, este propósito parece lograrse mejor si se nos propone una imagen desagradable, horrible incluso, que si se ofrece una imagen hermosa. Youtube sería su inagotable vertedero. El asco, que Kant había descartado en su Crítica del juicio, puede anidar en el centro de la experiencia estética.

Como ha estudiado Julia Kristeva (1980), el arte abyecto tiene que ver con el freudianismo y las fases oral, genital y anal, y por consiguiente con los orificios del cuerpo humano. Parte de su equívoco encanto reside en la riqueza semántica que contiene el adjetivo. Por un lado, obviamente, "abyecto" significa, según el DRAE, “despreciable, vil en extremo”, es decir, que el arte abyecto se señala a sí mismo como una vulneración de un supuesto orden moral que quedaría implícito y que en esa medida vendría a manifestarse desde un contrapunto. La infracción haría visible la ley. Pero, por otro lado, la etimología de "abyecto" - de ab iacio, "arrojar" - nos recuerda además un significado terriblemente literal y físico: el arte abyecto tiene que ver a menudo con los fluidos corporales o con partes del cuerpo que se desgajan violentamente de él, como sucedía en la performance de la guatemalteca Regina Galindo, "Mientras ellos siguen libres" (2006), en la que la artista se ató a la cama con cordones umbilicales para protestar por el drama de las mujeres embarazadas cuyos violadores seguían sin castigo. Como en este último ejemplo, el arte abyecto coincidiría con formas de expresión de origen artístico no objetivo - el happening, el Fluxus, el body art- que la cultura 
mediática ha trivializado en nuestros días hasta la extenuación. El resultado, según comprobamos a diario en nuestros televisores y nuestras calles, esto es, en nuestra cultura, es un imperativo único: el de que hay que llamar la atención a cualquier precio. ${ }^{1} \mathrm{La}$ abyección ma non troppo sólo enarbola un gesto de rebeldía y transgresión domesticadas, una ruptura de expectativa desactivada de antemano, porque en la medida en que queda codificada pasa a integrarse en la retórica de lo previsible.

En su origen, sin embargo, cabe decir que el arte abyecto puede poseer cierta pertinencia. Como se estableció en el catálogo del Museo Whitney de Nueva York sobre Arte abyecto: deseo y repulsión (1993), el arte así llamado se realiza con materiales como cabello, sangre, semen, etc., con el fin de "enfrentarse a los tabúes". Abyecto, ha definido también Julia Kristeva (1980: 11) es "aquello que perturba un orden, una identidad"; su propósito primero consiste pues, en turbar al espectador, provocar en él una conmoción; sin embargo, a continuación Kristeva señala que "todo crimen es abyecto pero el crimen premeditado, la muerte solapada, la venganza hipócrita lo son más aún porque aumentan la exhibición de la fragilidad legal”. La abyección consistiría a menudo en la manifestación de una alevosía tan oculta como estructural y omnímoda, y nos conduciría hacia la denuncia, o al menos la

${ }^{1}$ También se caracteriza por una estrategia semántica muy reducida: la que establece que ese propósito se logra mediante el desnudo descontextualizado. ¿Hay que protestar por la retirada de un programa de becas? Los estudiantes se desnudan en la calle. ¿Por los recortes en el presupuesto del cuerpo de bomberos? Los bomberos se desnudan en la calle. ¿Por el maltrato a los animales? Los activistas se desnudan en la calle. 
reflexión, sobre formas de violencia a menudo atávicas y perennes, pero en ocasiones multiplicadas potencialmente por la biopolítica moderna. El arte abyecto sólo mostraría en crudo esa verdad incómoda que cínicamente callamos a diario.

En ese sentido cabe decir que el carácter abyecto del primer ejemplo que he citado, pese a su trivialidad anecdótica, ofrece más de una posibilidad hermenéutica. Puede contemplarse como una celebración orgiástica espantosa que atentaría contra algunos elementos basales de nuestra cultura: el cuidado del más débil, la asociación entre comida y hospitalidad, la iconografía navideña del Niño, etc. Puede contemplarse como una "liturgia" que atenta contra uno de los elementos centrales del judeocristianismo, a saber, la prohibición de los sacrificios humanos, e incluso como un recordatorio o una siniestra inversión del simbolismo nutricio que se realiza en los ritos centrales de esta religión, tanto en el Sabbath como en la eucaristía. Puede incluso contemplarse como una advertencia sarcástica del carácter de "holocausto" que posee toda obra de arte, en la que se arrebata cierta porción de materia a la realidad literal de la vida para reelaborarla estéticamente y en esa medida destruirla (es decir, que se niega un elemento presente para propiciar un futuro), perspectiva que alcanza su extremo en la snuff movies sobre las que discurrieron Joel Schumacher en Asesinato en 8 mm ( 8 mm, 1999) y Alejandro Amenábar en Tesis (1996) y que constituyen documentaciones de un auténtico sacrificio; en la medida en que el asesinato alevoso se realiza para poder filmarlo, las snuff movies supondrían esa misma lógica. $\mathrm{O}$, si se recuerda la etimología de "abyecto", nuestro fotomontaje puede contemplarse, por qué no, como una denuncia del carácter de "cosa" al que ha quedado reduci- 
do el nasciturus en la civilización occidental, desde una sugerencia tan horrísona como pertinente: con su banquete, los comensales reducirían ese "objeto" a pura cantidad material y, mediante el proceso alimenticio, lo incorporarían a su propio metabolismo, es decir, lo volatilizarían en aras de la única subjetividad que la cultura y la ley contemporáneas reconocen.

Regresaré más tarde sobre estas cuatro interpretaciones, pero quisiera detenerme ahora en una quinta: la que sencillamente subraya el carácter morboso de la experiencia estética suscitada por semejante imagen. Una disposición, de nuevo, inquietante, porque el objeto que se propone a nuestra mirada despierta en nosotros tanto un juicio censor como una momentánea —o, en según qué casos, no tan momentánea- fascinación. "Si tu razón moral te susurra al oído que soy tan repugnante, que deberías rechazarme para considerarte digno”, vendría a decir irónicamente la imagen, “¿por qué, querido espectador, sigues ahí, contemplándome?”.

\section{Qué importa}

Por supuesto, esta dualidad paradójica, esta fascinación por lo obsceno en el sentido más literal y este feísmo estridente no son muy novedosos. Cabe remitirlos a un linaje tan eximio como el de Baudelaire. En "Una charogne", por ejemplo, el poeta recuerda la anécdota de un paseo en compañía de su amante durante el cual ambos encontraron el cadáver en descomposición es decir, "abyecto"- que anuncia el título. La pieza no ahorra los detalles descriptivos: el olor nauseabundo, la posición imposible del cuerpo, el vientre pútrido, las moscas que zumban a su alrededor, los gusanos que devoran ese despojo... El desenlace final, no obstante, resuelve esa confrontación con el 
objeto — con lo obsceno- mediante una reintegración a la subjetividad, de la mano de una reflexión moral: Et pourtant vous serez semblable á cette ordure, I á cette horrible infection, / étoile de mes yeux, soleil de ma nature, / vous, mon ange et ma passion! (Baudelaire, 1950: 50). Una reflexión, como se ve, moral ma non troppo: el poeta no se aplica la lección y la advertencia a sí mismo sino a su interlocutor. Sic transit gloria mundi: la hermosura presente ocultaría la semilla de una miseria definitiva que sólo causa repugnancia al espectador.

Más allá de esta anécdota y su resolución, el feísmo deliberado, como es sabido, formaba parte sustancial de la iconografía baudeleriana. También su profesión de amoralidad, en congruencia con la autonomía de lo estético heredada del dandismo de su maestro Barbey d'Aurevilly. El propio título de su poesía completa - "flores", pero "del mal"- parece anunciar provocativamente esa asociación entre lo bello y lo perverso. De hecho, "Hymne á la beauté" enuncia resueltamente esta autonomía del modo más elocuente posible:

Que tu viennes du ciel ou de l'enfer, qu'importe,

O beauté! monstre énorme, effrayant, ingénu!

Si ton cil, ton souris, ton pied, m'ouvrent la porte

D'un infini que j'aime et n'ai jamais connu?

De Satan ou de Dieu, qu'importe? Ange ou Sirène,

Qu'importe, si tu rends - fée aux yeux de velours,

Rythm, parfum, lueur, ô mon unique reine!-

L'univers moins hideux et les instants moins lourds? (45) 
Nada importa pues que tras la belleza se oculte Dios o el diablo, lo esencial reside en embriagarse de ella -Énivrez vous!, grita uno de los Petits poèmes en prose- y suspender así la languidez de los sentidos, trascender la norma de mediocridad anodina que rige la existencia: la estética baudeleriana pondría de manifiesto la rebelión moderna contra la convertibilidad de los trascendentales, sí, pero al subrayar la intensidad de lo estético sugeriría antes que nada la sacramentalidad circular de esta experiencia de lo bello, que no nos remitiría a nada salvo a sí misma. En ella residiría la única salvación, la única vía para eludir el tedio, el ennui. El arte consistiría así en una celebración estéril, el ejercicio de un escapismo tan momentáneo como fútil. Liturgia o akelarre, tanto da. Qu'importe!

Ahora bien, no debe olvidarse que el punto de partida de Les fleurs du mal era precisamente la constatación de ese ennui como pieza clave del arco de la sensibilidad moderna. Y su proclamación, en "Au lecteur”, el pórtico del libro, arrojaba al rostro del lector una declaración tan turbadora como la imagen del fotomontaje que he comentado arriba: el ennui es, entre los chacales, las panteras, los simios, los escorpiones, los buitres y las serpientes de la conciencia, el peor de nuestros vicios y el más horrendo de nuestros monstruos, quizá porque refuta la cultura judeocristiana desde su relato fundacional: contra un Dios que ante la Creación sanciona que todo "era bueno", el poeta declara que sólo eso, ese disgusto, esa pereza de vivir, le inspira el mundo. Y lo hace de un modo terrible y certero, mediante una nueva reintegración a la subjetividad: lo cierto es que, contra los gestos de repugnancia y las expresiones de censura de la hipocresía decimonónica, el lector conoce tanto como el autor ese estado de ánimo. C'est l'ennui! — L'oeil chargé d'un pleur involon- 
La cultura: ¿liturgia o akelarre?

taire, / Il rêve d'échafauds en fumant son houka. / Tu le connais, lecteur, ce monstre délicat, / -Hypocrite lecteur, mon semblable, mon frère! (Baudelaire, 1950: 28).

Creo que la radicalidad de Baudelaire no debe tomarse a broma: su apóstrofe, su interpelación al lector, su vindicación feísta e inmoral, acontecen precisamente en un lenguaje de extrema delicadeza. De ahí el efecto punzante de la ironía: la declaración del atractivo del vicio y la fealdad tiene lugar en un poema de perfectos alejandrinos, en un ritmo y una dicción que habían pulido el idioma hasta el extremo, liberándolo de la hojarasca de poetas como Lamartine o De Vigny. En esa eufonía y euritmia consumadas aparece la profesión baudeleriana. Pero ésta además oculta una lógica que el poeta desarrolla en sus diarios, Mon coeur mis à $n u$, y que viene aquí muy al caso: precisamente porque en el relato del Génesis Dios juzga el mundo "bueno" deduce Baudelaire que la única posibilidad que le queda al poeta de sentirse creador reside en el mal. Añadir bien al bien sólo supondría un ejercicio reiterativo. Con su teología de la revuelta, Baudelaire conculca pues la idea más clásica del arte y de la condición del artista en el judeocristianismo. Desde una actitud rabiosamente prometeica, el autor de Les fleurs du mal establece que su cometido consiste en rivalizar con Dios y que el único espacio que Yahvé le ha dejado disponible se encuentra en el mal. La transgresión será su gramática y su retórica.

\section{Crimen perfecto}

No me he alejado, pese a lo que pueda parecer, de la imagen inicial. Al igual que este Baudelaire, aquella pieza de arte abyecto puede leerse como una exaltación del mal que se obtiene como inversión directa y premeditada 
de lo habitualmente tenido por "bueno" en nuestra cultura; y, también al igual que Baudelaire, su propósito más obvio e inmediato, aunque no necesariamente incompatible con otras interpretaciones, es provocar esa disposición irónica en la conciencia y subrayar el carácter morboso de la experiencia estética. El objeto convierte al espectador desprevenido en una suerte de voyeur del horror.

Algo parecido logró Alfred Hitchcok con La soga (The Rope, 1948): la historia de dos jóvenes que deciden asesinar a un tercero sin otro propósito que el de cometer un crimen perfecto. En realidad, la película se basa en una obra de teatro de Patrick Hamilton y ésta a su vez en unos hechos acaecidos el 21 de mayo de 1924 en Chicago: ${ }^{2}$ el asesinato de Bobby Franks, un niño de trece años, a manos de Richard Loeb y Nathan Leopold, de dieciocho y diecinueve de edad respectivamente. Un caso que conmocionó a la opinión pública, entre otras razones por la nula motivación social y económica Loeb era hijo del vicepresidente de los pujantes Almacenes Sears, Leopold un cultísimo estudiante, aficionado a la ornitología - y por la crueldad de los asesinos, que tras acabar con la vida de la víctima transportaron el cadáver en un coche y lo abandonaron en un conducto subterráneo de las afueras. ${ }^{3}$

${ }^{2}$ Como consignó François Truffaut (167), la adaptación del texto de Hamilton corrió a cargo de Hume Cronyn y del propio Hitchcock; Arthur Laurents trabajó algunos de los diálogos, aunque otros son directamente los de la pieza de Hamilton.

${ }^{3} \mathrm{Su}$ torpeza, sin embargo, fue definitiva: Leopold se dejó en el lugar sus anteojos, que contaban con un novedosísimo sistema de apertura que sólo tres personas tenían en Chicago en aquel momento, y fueron detenidos y hallados culpables. 
El desgraciado episodio constituye el trasfondo de películas como Impulso criminal (Compulsion, Richard Fleischer, 1959) y Asesinato 1, 2, 3 (Murder by Numbers, Barbet Schroeder, 2002) y de piezas literarias como el mencionado drama de Hamilton o la novela de Meyer Levin de 1956, homónima de la película de Fleischer. No obstante, la película de Hitchcock tiene algo de lo que carecen los demás relatos: la complacencia irónica en el esteticismo de los personajes y de la escenografía. En La soga, Brandon es un agudo intelectual, amigo de la conversación y dueño de un wit punzante, mientras que Philip, aunque más apocado, es un consumado pianista; ambos visten trajes caros, comparten un ático con vistas al skyline de Manhattan y han estudiado en Harvard. Es decir, son dos WASPS acostumbrados al lujo y educados en las elitistas instituciones a las que los norteamericanos pudientes envían a sus hijos. Una versión tardía y pasada de rosca de personajes como Robert de Montesquiou, Oscar Wilde o J. K. Huysmans.

De hecho, La soga elude tanto los preparativos y la ejecución del crimen - la víctima, David, muere en el primer plano de la película - como el proceso judicial al que se verán sometidos los asesinos: su interés se focaliza sobre la difícil relación entre estos dos estetas, que han decidido darle otra vuelta de tuerca a la situación: poco después de asesinar a David con la soga del título, lo introducen en un arcón y celebran sobre él una cena a la que invitan a la novia, el padre, la tía y un amigo de la víctima, junto con un profesor de sus tiempos de internado. Y la morosa disposición de la tramoya el mantel, los candelabros, las bandejas con las viandas, las destellantes pitilleras de oro, etc.- convierte el arcón en un altar y el ágape en un rito sacrificial. Los comensales celebran sin saberlo el holocausto de David, que 
yace a escasos centímetros de las poses galantes y los comentarios ingeniosos, en una enfermiza ironía. El hecho de que sea la primera película de Hitchcock en color $-\mathrm{y}$ de que al rodarse todo en una única estancia el filme adquiera una cualidad dramática palpable, en la que todo obedece a un cálculo exhaustivo, sin la apertura a lo aleatorio que cabe esperar en un rodaje al aire libre y en escenarios reales- acentúa este regodeo estetizante. El akelarre se obtiene del exagerado y vicioso refinamiento de lo puramente exterior de la liturgia.

Por supuesto, el texto de La soga cuenta con una fuente fácilmente identificable: Nietzsche. Una de las tesis que sostiene Brandon durante la velada es la existencia de una raza de hombres superiores, semejante al Übermensch nietzscheano. "El asesinato es un crimen para el hombre medio, pero un privilegio para los elegidos", dice. "El único crimen es ser débiles", afirma también. De hecho, el nombre de Nietzsche se menciona en uno de los debates, y no sin razón: si contra algo arremetía su Genealogía de la moral era contra la "moral de esclavos" que se interponía en la espontaneidad del individuo vigoroso. Y el modo de llegar a un nuevo estadio, de acuerdo con este darwinismo ético, era precisamente el sacrificio de ese hombre del que el filósofo alemán declaraba estar "cansado". "El sacrificio del hombre en bloque para la prosperidad de una única especie humana más fuerte”, sostenía en el primero de los tres ensayos que componen el libro, "eso sería el verdadero progreso" (Nietzsche, 1997: 52). Brandon y Philip estarían por tanto realizando el acto fundacional de una nueva cultura: una que, invirtiendo el contenido del Gólgota, no proclama la prohibición sino la sanción de según qué sacrificio humano. 
Por si esto no bastase, el conjunto de la celebración ideada por Brandon y Philip remite a la Genealogía a través de algunas pinceladas de los diálogos. Cuando Brandon afirma que "el poder de destruir es tan satisfactorio como el poder de crear" nos recuerda la vindicación sádica de Nietzsche por la vía más literal: "Hacer que alguien sufra, he ahí el verdadero banquete" había dicho el filosofo. De ahí, a su juicio, que en algunas culturas las fiestas a menudo fuesen acompañadas de ejecuciones, autos de fe, exhibiciones como las de los gladiadores o torturas. "Sin crueldad no hay fiesta" (1997: 43), zanjaba Nietzsche. Así, David constituiría, en el lenguaje de Giorgio Agamben (1998), una suerte de bomo sacer necesario, el que Philip y Brandon requieren para apuntalar su violencia gratuita y arbitraria, despojada de todo interés salvo la pura voluntad de infligir el daño, como un voluptuoso acto de autoafirmación. Es decir, como un acto estético en la medida en que carece de finalidad práctica alguna. Otros — como Roger Caillois y Georges Bataille, una de las referencias fundamentales en la historia de la reflexión sobre lo abyecto- soñaron también con fundar una nueva cultura mediante un sacrificio humano, en los tiempos de la revista Acéphale, pero permanecieron en el diletantismo de parlotear incansablemente sobre las ideas de Nietzsche; Philip y Brandon se dicen superiores precisamente porque han osado perpetrar el crimen.

Obviamente, el discurso de Brandon - y la premisa mayor del relatoincide sobre la supuesta insustancialidad de las normas morales: la idea de que constituyen un mero constructo, producto de la costumbre, como sugiere la etimología de mos, -ris, cuando no un subterfugio ideado por los débiles para someter a los fuertes. $\mathrm{Y}$ ése era precisamente el punto de partida de 
Nietzsche, la pregunta autorrespondida que yace en la base de su discurso: su lamento, al inicio de su libro, es que los moralistas del empirismo inglés dan por supuesto que la moral es esencialmente ahistórica, y de ahí la cuestión que su ensayo intenta resolver: “¿Bajo qué condiciones inventó el hombre los juicios de valor sobre lo bueno y lo malo?” (Nietzsche, 1997: 5). La cursiva es clamorosamente mía, porque delata que toda esa indagación "arqueológica" o genética parte de un supuesto tan dudoso como divulgado: si Nietzsche goza de una posteridad halagüeña es precisamente por haber logrado que pensemos lo moral no como una ley escrita en el corazón del hombre - que, obviamente, es preciso actualizar y sacar a la luz - sino como un añadido a la vida, la sobreimposición de algo que no estaba en ella en absoluto y que cercena sus posibilidades. La apertura hacia el triunfo de la fuerza bruta y de la voluntad ciega, o hacia fenómenos como el iuspositivismo — una de las afirmaciones más tajantes de la Genealogía es que carece de sentido preguntarse si un acto es justo o injusto per se, sólo cabe calificarlo como tal por referencia a un código de leyes- se me antoja palmaria.

No obstante, hay en la película de Hitchcock una segunda fuente menos obvia: el brillante y célebre ensayo de Thomas de Quincey, On Murder Considered as One of the Fine Arts (1829). De hecho, De Quincey nos devuelve no sólo a La soga sino a la imagen que era nuestro punto de partida, porque su ensayo arranca con una reflexión sobre un sarcástico antecedente: el texto titulado Una modesta proposición destinada a evitar que los niños de Irlanda sean una carga para sus padres y el pais, de Jonathan Swift: allí el autor de Gulliver's Travels — irlandés de origen, no debe olvidarse - sugería que la solución para la superpoblación y la hambruna era cocinar a los niños irlandeses y 
comérselos, en un malthusianismo avant la lettre tan sarcástico como políticamente pertinente ${ }^{4}$.

Claro está que De Quincey no pretendía incitar a nadie al asesinato. Su ensayo constituye más bien un brillante divertimento, que viene aquí al caso en atención a su punto de partida: la disyunción moderna entre los trascendentales, cuya convertibilidad —según expondría, como hemos visto, un Baudelaire que fue precisamente el traductor de De Quincey al francés- se nos antoja problemática. Al fin y al cabo, De Quincey era, además de un gran latinista, un germanófilo formado en la lectura de Kant y un amigo de los poetas de los Lagos, especialmente de un Coleridge que había introducido la filosofía trascendental y el idealismo de Schelling en las letras inglesas. Y ¿qué exigía el regiomontano como condición de la experiencia estética? El desinterés, es decir, una cierta des-realización del objeto, que subrayaba su distancia respecto de la subjetividad del espectador. Contemplar un asesinato como una consumada obra de arte era posible desde el momento en que lo bello no tenía por qué ser bueno ni verdadero. "El asesinato puede tomarse por su lado moral” explica De Quincey, “como suele hacerse en el púlpito o

${ }^{4}$ Los paños calientes que el bueno de Thomas aducía a continuación para restar parte de su crudeza a la propuesta de Swift serían hoy innecesarios y ridículos, después de toda la narrativa victoriana sobre el drama de los huérfanos y las instituciones caritativas, de Austen a Dickens, si no fuese porque nuestra refinada cultura del estado del bienestar y el capitalismo internacional ha dado con una solución mejor que la de Swift: convertir al nasciturus no en el alimento del adulto, pero sí en la materia prima de sus productos cosméticos. Una metáfora fabulosa, pues si algo ha logrado esa cultura ha sido maquillar la realidad trágica e incontestable de la vida, la nuda vida sobre la que ha teorizado Agamben, hasta volverla irreconocible. 
en el juzgado, y, lo confieso, ése es su lado malo; o bien cabe tratarlo estéticamente - como dicen los alemanes-, o sea, en relación con el buen gusto" (De Quincey, 1981: 20). Cuando un asesinato aún no se ha cometido debemos evitarlo, pero cuando ya ha tenido lugar sólo podemos evaluarlo desde esa óptica. "Ya hemos dado lo suficiente a la moralidad", concluye De Quincey, en un cinismo provocativo, "ha llegado la hora del buen gusto y las bellas artes”. Así, la experiencia estética dejaría en suspenso el juicio moral para considerar la belleza, o la falta de belleza, del objeto, y de hecho eso hacemos a diario, hasta cierto punto, cuando leemos una novela o un poema. Con su esteticismo rampante, Brandon y Philip habrían llevado la lógica puramente humorística de De Quincey varios peldaños más allá. Cometer el crimen perfecto y no mostrárselo a nadie, dice uno de ellos en el arranque de la película, "sería como pintar un cuadro y no colgarlo". Su narcisismo, su complacomplacencia en la coreografía primorosa del akelarre, será su perdición.

\section{Otro sacerdocio}

No quiero decir con todo lo anterior que el arte abyecto - y sus ramificaciones: el arte "extremo", "degenerado", etc.- sea una novedad absoluta. Como ha observado Joseph Leo Kerner (1997), el elemento abyecto ha estado presente desde antiguo: basta recordar La lección de anatomía, de Rembrandt, o su Buey deshollado; lo que sí es cierto es que desde el urinario de Duchap y, sobre todo, desde el surrealismo, la exploración de estados de conciencia menos luminosos, como los que suscita el arte abyecto, son mucho más frecuentes. Tampoco pretendo sostener que se trata de la única tendencia hoy vigente, pero sí que forma parte de un lenguaje cada vez más 
divulgado, frente al cual una belleza apolínea rezuma, por contraste, una gazmoñería insoportable a la sensibilidad hodierna: si algo no persigue el arte moderno es el pulchrum que guiaba al peregrino de la Divina Comedia.

En realidad, ni siquiera vengo a afirmar que toda manifestación artística recurra hoy al reciclaje monstruoso de algunos elementos de la religión cristiana. Lo que sí quisiera recordar es que ese recurso de la cultura moderna a la subversión de lo religioso no resulta tan descabellado. Desde las instalaciones con hostias consagradas hasta las procesiones en las que se hace mofa del Crucificado o se presenta a la Virgen María como una drag queen, pasando por las exposiciones de crucifijos bañados en orina o las celebraciones de carnaval abiertamente ofensivas, las manifestaciones de esa cultura nos recuerdan una y otra vez su voluntad de fundar una nueva humanidad. Y la religión cristiana se presta inmejorablemente a todas estas distorsiones y desfiguraciones — de signo más o menos abyecto— no sólo porque gran parte de su iconografía, como la propia de la Semana Santa, insiste en las imágenes del dolor y la crueldad, sino porque el centro de su mensaje, la Encarnación, ha situado a Dios en una posición vulnerable. El arte abyecto, con Dios como objeto en su literalidad física, es impensable en el sintoísmo, el taoísmo, el budismo, incluso en el judaísmo o el Islam, porque en estas religiones Dios no posee encarnadura alguna. En cambio, en el cristianismo Dios ha habitado el espacio y el tiempo, se ha sometido a una carnalidad frágil cuya indefensión se muestra de modo definitivo en la Crucifixión. Y, por otra parte, esa Encarnación en la que se unen lo finito y lo infinito constituye la metáfora fundamental de lo estético. 
En cualquier caso, creo que a la vista de estos ejemplos históricos no cabe negar a) la problemática convertibilidad de los trascendentales en la cultura moderna, b) la apertura al feísmo y la inmoralidad que esta convertibilidad frustrada supone; c) la voluntad expresa de mostrarla mediante la contradicción abierta, que se manifiesta en la presentación del mal como "bello" o "artístico"; y d) la lógica de la subversión de lo religioso en la que este proceso culmina, en la medida en que se percibe en la religión lo tradicionalmente calificado como "bueno" que la nueva cultura pretende abolir. En suma, para el espectador moderno a menudo el cristianismo aparece como incompatible con la cultura moderna, en una lógica bastante lineal: el romanticismo trae consigo una exigencia de "creación" que invita a la ruptura con la tradición y atenúa el aspecto mimético de la actividad artística; la creación exige a su vez la novedad y ésta el destierro de todo cliché; la forma más evidente de procurar esa novedad se encuentra en la transgresión; y las manifestaciones más radicales de transgresión son probablemente el sacrilegio y el sacrifico humano. Ambos vocablos comparten la misma raíz — sacer, "prohibido"- que a través de la etimología nos llevan a ese origen oscuro y atávico que se ocultaría tras la cultura.

Durante algunas décadas, entre la época de fin-de-siécle y la vanguardia, esta incompatibilidad entre judeocristianismo y cultura moderna se hizo manifiesta y dio lugar a fenómenos como la afición a la nigromancia, el espiritismo o el satanismo. No en vano había dicho Nietzsche, en su habitual lógica de la transmutación de los valores, que los gerreros que conquistaban y sometían eran "los auténticos representantes de la cultura", mientras que las razas sometidas a la "moral de esclavos" representarían "el declive de la 
humanidad". Sabios, escribas, sacerdotes, monjes, los supuestos "instrumentos de cultura" sólo suponían a juicio del filósofo "una desgracia para el hombre, o un argumento contra 'la cultura' en general" (Nietzsche, 1997: 24).

Hubo quien ante la disyuntiva optó por la cultura moderna, como Apollinaire, y quien lo hizo por el cristianismo, como Eliot. Ambas opciones, sin embargo, delataban esa premisa común. Uno de los casos más manifiestos es el de James Joyce. De hecho su relato autobiográfico, Retrato del artista adolescente, fundamentalmente da razón de esta trayectoria compartida por tantos y tantos hombres de letras de los últimos dos siglos: de la educación en un colegio regentado por una orden religiosa a la resolución adulta de abandonar el cristianismo. Las discusiones sobre religión -y sobre las particularidades del catolicismo irlandés en medio del conflicto político- son constantes a lo largo del relato. También las polémicas sobre literatura y estética, en las que Newman queda encumbrado como el mejor de los prosistas, mientras que Tennyson y Byron se disputan los laureles del verso. A través de ellas, lo que poco a poco va abriéndose camino en la conciencia del protagonista, Stephen Dedalus, es que el cristianismo tal y como él lo conoce exige una renuncia al mundo - qué habrían llegado a ser en él aquellos jesuitas tan capaces, se pregunta- y que por consiguiente su voluntad de entregarse a la literatura, es decir, a una actividad "mundana", lo obliga a dejar de lado las exigencias de la religión. Es la resolución que tiene lugar en uno de los diálogos finales:

Te voy a decir lo que haré y lo que no haré. No serviré por más tiempo a aquello en lo que no creo, llámese mi hogar, mi patria o mi religión. Y trataré de expre- 
sarme de algún modo en vida y en arte, tan libremente como me sea posible, tan plenamente como me sea posible, usando para mi defensa las solas armas que me permito usar: silencio, destierro y astucia [...] No me da miedo de estar solo, ni de ser pospuesto a otro, ni de abandonar lo que tenga que abandonar, sea lo que sea. No me da miedo el cometer un error, aunque sea un error de importancia, un error de por vida, tan largo tal vez como la misma eternidad (Joyce, 1978: 28081).

Claro está que bajo esta resolución joyceana corre un rechazo del provincianismo y el tradicionalismo irlandeses que el autor sentía que asfixiaban su impulso vital y creador. También, por supuesto, corre un rabioso individualismo, que sólo puede expresarse a sus anchas desde el exilio, esto es, desde el alejamiento de ese medio que percibe como opresivo. Lo que me parece más digno de reseñar, sin embargo, es que la resolución de Dedalus reintroduce lo religioso por medio de la lógica de la secularización: su futura dedicación al arte, a la escritura, se propone como un remedo del sacerdocio, como un sacerdocio alternativo, en una lógica muy parecida a aquella que se oculta tras la obra de un Rilke, un Juan Ramón Jiménez o un Pessoa. Y, por tanto, como una tentativa de salvación. Y Joyce no está solo en esta actitud: la entrega del artista o el escritor modernos a su misión se antoja demasiadas veces conducida por una lógica sacrificial, sólo que en un bucle siniestro el sacrificio acontece a menudo en el altar de la propia obra, de la propia gloria. La cultura ofrece entonces la apariencia de un culto idólatra. Una forma de akelarre menos sanguinolenta tal vez, pero al fondo de la cual se entrevé el callejón sin salida de la esterilidad. 


\section{Antídotos y tentaciones}

Creo, sin embargo, que contra estos conflictos entre cultura moderna y cristianismo existen varios antídotos que conviene recordar. En primer lugar, contra la esthétique du mal de la que el arte abyecto sería un enésimo capítulo, contra esa complacencia en lo perverso que asomaba ya en Baudelaire, cabe proponer... al propio Baudelaire. Sí, porque con su interpelación al lector Baudelaire conculcaba tanto la hipocresía en cuanto moral pública del Segundo Imperio como el buenismo rusoniano que hacía oídos sordos a los vericuetos menos complacientes de la conciencia, ocultando así el rostro auténtico del hombre. La antropología del poeta, como queda claro en sus diarios, era antes que nada un recordatorio del pecado original y una denuncia de los sustitutos de la gracia que la modernidad proponía. La doctrina decimonónica del progreso, por ejemplo. "El verdadero progreso", afirmaba Baudelaire, "no consiste en la instalación del alumbrado urbano sino en la medida en que el hombre borra las huellas del pecado original". Y, por consiguiente, en la cultura - y no en la natura, como defendía Rousseau - se encuentra la esperanza. Sobre todo, en Baudelaire hay un antídoto no sólo debido a la lucidez sin componendas de su diagnóstico oscuro sobre el hombre sino porque, como advirtió Sartre (1957), en la medida en que el poeta se rebelaba contra Dios y el Bien estaba calificando ese Bien como tal. Es decir, que en lugar de proponer una inversión de los valores como Nietzsche confirmaba al Bien en su sitio aunque sólo fuese porque lo necesitaba allí para rebelarse contra él.

En segundo lugar, contra el extremo al que conduciría la apología del mal y la abyección —el sacrificio humano de Zhu Yu, de Leopold y Loeb, de $L a$ 
soga, de Caillois y Bataille, de las snuff movies - en Dostoievski hay un antídoto de antemano: la figura de Sonetchka - una imago Christi, se sugiere en el capítulo II de Crimen y castigo- que llevada por el amor se entrega hasta el extremo, se despoja de sí misma. Y con su sacrificio Sonetchka "rompe el saque" al protagonista de la novela, Raskolnikof, que pretendía fundar una nueva humanidad con el asesinato de la vieja usurera. Debe tenerse en cuenta que con su acto radical — "el hecho", lo llama el torturado estudiante- Raskolnikof pretendía liberar a los oprimidos del mundo: su hermana Dunia, Lisbeth, la hermana de la usurera, la propia Sonia, etc. Es decir, que su crimen contenía una imagen invertida del sacrificio del Gólgota, donde sacerdote y víctima son una y la misma persona. Sin embargo, en la expiación de su cautiverio Raskolnikof experimenta por primera vez un amor que no había previsto en su edificio intelectual y se siente "regenerado", leemos en las paginas finales de la novela. En los últimos párrafos, abre por primera vez un Evangelio, regalo de Sonia, y así comienza "otra historia, la de la lenta renovación de un hombre, su paso gradual de un mundo a otro y su conocimiento escalonado de una realidad totalmente ignorada" (Dostoievski, 1964: 543). La auténtica novedad había estado ahí siempre, ante sus ojos.

Un tercer antídoto se encuentra en el regreso a una de las fuentes del pensamiento de De Quincey y Baudelaire: Coleridge. Si la cultura moderna, desde su origen romántico, pretendía alzarse contra la divinidad, rivalizar con ella, el regreso a uno de sus fundadores viene muy al caso tanto para enaltecer la propia cultura como para conocer bien sus límites. ¿Por qué? Porque en el párrafo decisivo y archicitado de Biographia Literaria Coleridge dice exactamente que la imaginación —esto es, la facultad suprema del conocimiento y 
la creatividad - constituye "un eco en la mente finita del infinito Yo soy" (Coleridge, 2012: 493), de acuerdo con la traducción que desde la Biblia del rey Jaime ha tenido la frase del Éxodo en la lengua inglesa. Ni que decir tiene que, junto con el poso del idealismo alemán y su idea "constructivista" o poiética del conocimiento, la propuesta de Coleridge supone una exaltación de esta facultad creadora que yace en la raíz del romanticismo: el poeta sería un semidiós. Pero, conviene advertirlo, sólo "semi”: el poeta sólo profiere un “eco", no la propia "voz" de Dios. Su creación no acontece ex nibilo, posee un carácter secundario.

Un cuarto antídoto se colige del anterior. Si se remonta el camino de la etimología se comprueba que "cultura" deriva de cultus, "cultivo", "cuidado", y éste a su vez de colo colui cultum, "cultivar", "cuidar". La cultura no se hace sobre la nada sino a partir de una materia preexistente. Como el agricultor que labra su tierra, el arte y la cultura en todas sus manifestaciones consistiría en un trabajo: la transformación de algo dado en otra cosa, que hace el mundo más habitable porque añade un elemento que no se encontraba en la naturaleza misma. Lo cual significa, por supuesto, que si no desea ser fútil y absurda la cultura y el arte han de ser un servicio, algo que se hace para otro. Pero también que no somos ángeles, que vivimos en el espacio y el tiempo, que necesitamos esa mediación de los textos y las imágenes para hacernos con el mundo... y para atisbar lo que haya más allá de él. No podemos habitar la mera naturaleza. En ese sentido la cultura en su conjunto posee un carácter "interpretativo", es decir, que se encuentra sometida a los cambios históricos: por eso es preciso verter constantemente el vino viejo en odres 
nuevos. La cultura no sería pues tarea demiúrgica, se parecería más bien a la de Adán antes de la caída.

De hecho, si se vuelve la mirada al relato del Génesis se comprueban al menos dos cosas. Una, que Adán posee lenguaje y pone nombre a los animales; pero, dado que la Creación es un acto verbal $-\mathrm{y}$ que, pese a la formulación inevitablemente sucesiva del lenguaje humano, no hay diferencia entre el decir Yahvé "Hágase la luz" y el traer la luz al ser- eso significa que al nombrar y conocer la naturaleza de las cosas Adán está "leyendo" el lenguaje de Dios, es decir, de nuevo está "interpretando". No en vano los autores paleocristianos hablaron del liber naturae, que junto con el de las Escrituras contendría la Revelación. O sea, que muy pronto habría algo añadido a la naturaleza, que sólo podemos designar como cultura, y ese algo, en la medida en que supone una interpretación, contendría una verdad, por remitirme al título del libro de Inciarte (2016).

Lo segundo que cabe decir sobre el relato del Génesis en este punto es que esa actividad cultural nos habla del modo del ser del hombre y del mundo. "Dominar" la tierra y "someterla" significa roturar los campos y adiestrar a los animales, por supuesto, pero más ampliamente desentrañar el comportamiento de la naturaleza y recrearla, de modo que ciencia y arte estarían sugeridos en la frase. Lo cual significa que, sí, Dios juzga "bueno" pero ese mundo no está cancelado, existe en la dimensión temporal y en él ha situado el Creador a un peculiar ser, material y espiritual a la vez, que por tanto puede conocer al Creador y al mismo tiempo habitar ese universo material y operar sobre él; en definitiva, que el mundo, aunque "bueno", es perfectible. $\mathrm{Y}$ esto significa a su vez que el hombre, el encargado de esa recreación, es en 
cierto modo "co-creador". Es decir, que existiría la cultura antes de la caída y que por tanto no puede considerarse que la cultura sea exclusivamente un resultado del pecado (aunque sí que constituye una de las estrategias para combatir sus efectos). La imagen del jardinero habla por sí sola. En lugar de aquel demiurgo, el ser cultural, el hombre, es un cooperador de Dios.

Un quinto antídoto se encuentra en la contemplación de los orígenes históricos de este arte del akelarre, de esta atracción por la perfidia: el malditismo blasfemo y provocativo de Barbey d'Aurevilly, por ejemplo, que en su Diaboliques presentaba relatos como la de Reniant, un sacerdote renegado como su nombre sugiere, que se ufanaba en la tertulia del café de haber arrojado las hostias consagradas a los cerdos, para épater les bourgeois. Las bromas blasfemas de Villiers de l'Île, los relatos de Apollinaire como "L'enchanteur pourrissant" o el del padre Serafín, que se divierte abusando de su ministerio y consagrando los bollos de una panadería, los presbíteros satánicos que Huysmans retrata en Là-bas... Ahora bien, no es casualidad que la mayoría de estos escritores oscuros muriesen en la fe y la piedad: su descubrimiento fue que necesitaban que hubiese algo sagrado para que sus trasgresiones fuesen tales: de ahí que, cuando Reniant se jacta de su hazaña, sus compañeros de tertulia le adviertan que para que haya verdadero sacrilegio, verdadera ofensa a Dios, es precisa la fe, o de otro modo sólo cabe pensar que lo que ha arrojado a los puercos es simplemente pan. El mal, advirtieron muchos de los autores que he nombrado, sólo existe de forma secundaria, es subsidiario del bien y en él se encuentra la auténtica novedad. Conviene pues bajar los humos de la parodia ofensiva que con frecuencia toma la liturgia - la iconografía cristiana, en general- para enarbolar un gesto de histrionismo: en 
realidad, y cada vez más conforme constituye la norma, semejante provocación sólo es tal en la medida en que el público se deja arrastrar por la caja de resonancia de los media. $\mathrm{Y}$ en un momento histórico en el que cientos de europeos mueren a manos del fundamentalismo islámico - y miles de cristianos lo hacen, en todo el mundo- el carácter "osado" y "temerario" de estas expresiones se me antoja pueril. Para que supusiesen un verdadero acto de transgresión y valentía deberían apuntar en otra dirección. Lo que contienen es más bien la reiteración del argumento que toma al cristianismo como chivo expiatorio, en la actitud alevosa de quien sabe que no va a recibir una respuesta proporcional.

Ante el presente estado de cosas es fácil olvidar estos antídotos, cuando no desconocerlos por completo. El resultado, esa visión pobre y disminuida de la cultura que con demasiada frecuencia es posible encontrar entre los cristianos: adultos que sostienen con mucha convicción que es bueno que los niños lean, pero a los que jamás se les pasa por la cabeza abrir un volumen; padres que no dudan en gastar fortunas ingentes en llevar a sus familias a un parque temático, pero que nunca entrarían en un teatro; defensores de un sedicente "humanismo cristiano" que supuestamente inspira instituciones educativas donde, curiosamente, el humanismo ha quedado desterrado de los planes de estudio... Intentaré aventurar una enumeración de las tentaciones más frecuentes a las que se enfrenta el cristiano de hoy ante el hecho cultural. Y lo haré desde el punto de vista del escritor, que es el que más directamente me atañe (aunque cabe trasladar muchas de estas consideraciones, mutatis mutandis, a ámbitos de la cultura distintos del literario). 
Una primera tentación, y la más obvia, es la que podríamos llamar "asimilacionista": la del judeocristiano consciente de que el medio cultural es cada vez más hostil a sus convicciones. No es en absoluto mi propósito frivolizar sobre esta situación, tan cotidiana y a veces tan dramática. Sin embargo, no siempre se precisa una disposición "heroica" para resistir a esta tentación: el escritor judeocristiano que se enfrenta a ese medio hostil puede muy bien decirse que el carácter "objetivo" y "público" de la cultura lo exime hasta cierto punto de volcar sobre sus escritos ese tesoro de su intimidad. No tiene por qué existir una correspondencia perfecta y biunívoca entre lo que un autor siente, piensa y profesa en su conciencia y la parte de ese mundo privado que traslada a sus libros, los cuales persiguen un ámbito que no necesariamente se reduce a cuantos compartan las premisas fundamentales de su universo moral. Que exista esa correspondencia imperfecta no supone en sí un problema.

Lo que sí supone un problema es la dinámica a la que conduce naturalmente esa separación en compartimentos estancos entre el poeta que escribe y el hombre que sufre, en la expresión de Eliot: la serie de pasos, o de peldaños descendentes, que el escritor se ve tentado de dar en dirección hacia una deseada reconciliación con su medio. Primero, escribir no dando por supuesto que todo el mundo es judeocristiano; después, escribir dando por supuesto que no lo es; finalmente, escribir como si él mismo no lo fuese. El desenlace, obviamente, es que deja de serlo. Y aquí precisamente el carácter objetivo y público de la cultura actúa como un recordatorio de que lo que no se expresa muere asfixiado en el reducto de la intimidad. La tentación asimilacionista aparece pues como una suerte de pacto fáustico en el que el autor vende su 
alma a cambio de una vaga promesa de éxito, reconocimiento o, simplemente, vigencia.

Por supuesto, la contrapartida se me antoja obvia: en el preciso instante en que tiene lugar esa capitulación general el escritor, el productor de cultura de origen judeocristiano, deja de tener nada que proponer al mundo contemporáneo. Nada, es decir, que éste no posea ya de suyo. La asimilación supone la extinción. Ciertamente en un mundo relativista, presidido por un pensiero debole empeñado en proclamar el "debilitamiento de las estructuras del ser", ese autor puede aliviar su conciencia alegando que en realidad la contradicción en la que vive no es tal, sólo constituye una oposición aparente, producto no del ser auténtico de las cosas sino de su manifestaciones históricas. Si se continúa por ese camino se alcanza pronto un punto en el que sencillamente ha quedado abolido el principio de no contradicción y es posible predicar una cosa y la contraria, al mismo tiempo y sobre el mismo objeto. En lugar de pensar lo separado como unido, como quería el viejo idealismo, se intenta pensar lo abiertamente incompatible como compatible, en una dialéctica pseudohegeliana en la que todos los gatos son pardos. El autor asimilacionista se justificará con el argumento de que el suyo es simplemente "otro" modo de ser cristiano. Y tal vez tenga razón, eso probablemente sólo Dios lo sabe. Lo que no está tan claro es si es el mejor modo, el verdadera y honradamente suyo, de serlo.

Una segunda tentación se obtiene de la inversión de esta lógica asimilacionista. Es la que podríamos considerar como la tentación "numantina" y obedece a una especie de monaquismo secularizado: la idea de que en el ámbito de extramuros es imposible no ya la salvación sino, simplemente, el 
lenguaje, el diálogo, el enriquecimiento mutuo. De nuevo, el escritor judeocristiano cuenta con buenas razones para pensar así. Cualquier telediario se lo demuestra un día tras otro. El problema que yace en la raíz de esta tentación es que si se desarrolla durante cierto tiempo adolece de la misma esterilidad que la tentación asimilacionista: muy pronto la defensa numantina del halagüeño pero exiguo bastión deriva en una endogamia galopante, y ésta en una consanguineidad empobrecedora. En suma, deja de existir el diálogo porque quienes viven dentro de los robustos muros de la fortaleza carecen de novedad alguna que intercambiar. Y otro tanto sucede, a grandes rasgos, fuera de esos muros.

En el caso judeocristiano, y en particular católico, la tentación numantina casi viene a sugerir un regreso a momentos preconciliares o, por qué no, a una mentalidad contrarreformista, en la que el mundo católico se plegaría sobre sí mismo para salvaguardar una supuesta ortodoxia y no tendría nada que ofrecer a quien no se encuentre dentro de sus bien definidos límites. El resultado es con frecuencia una decadencia de lo artístico y lo literario. El arte vuelve la vista hacia estilos historicistas, en un kitsch deleznable del que la catedral de la Almudena sería un ejemplo paradigmático, concebido para confirmar los peores prejuicios que pueda albergar un no católico sobre el catolicismo; y la literatura degenera en una suerte de autoayuda, un discurso vicario carente de vitalidad y, desde luego, de exigencia estética. Un sucedáneo, un aguachirle presidido por la lógica del als ob. Una comunión en la impotencia que, eso sí, gracias a las nuevas tecnologías transmite a la velocidad del rayo sus trending topics, vídeos virales, me gustas y archivos compartidos. 
No niego que tras la tentación numantina se oculte cierta sabiduría. Sobre todo, más que en el numantinismo activo, en la disposición indolente o escéptica ante la cultura se esconde una actitud sabia: la del cristiano que sabe que los akelarres de la cultura moderna jamás alcanzarán el mismo estatuto de eficacia y realidad que los ritos de su liturgia, la de quien sabe que lo que acontece en la eucaristía es incomparable con nada que pueda propiciar una invención meramente humana. Sin embargo, tras la prudencia que pueda revestir esa actitud, en el mismo momento en que se convierte en una disposición activa o "numantina" incurre en un error letal: batirse en retirada y guarecerse en los cuarteles de invierno; es decir, dejar que toda la cultura, que todo el imaginario y el lenguaje vigentes, vengan dictados desde instancias hostiles. ¿Por qué supone esto un problema, si se vive dentro de los muros de la fortaleza? Porque cada vez que se desee hacer una descubierta el cristiano se verá obligado a empuñar las armas del enemigo y combatir según sus reglas. La victoria será imposible. Entregar el campo al adversario y luego lamentar que en ese campo proliferen las expresiones culturales hostiles al cristianismo constituye una lógica tan estrepitosa como cotidiana, en boca de muchos cristianos occidentales del siglo XXI.

Una tercera tentación es la idílica o "buenista", en gran medida producto inevitable de la anterior. Se trata a menudo de una reacción contra el feísmo, el malditismo o la esthétique du mal que ya he comentado: ante ese arte "agresivo", nada complaciente, que ha desterrado la belleza o incluso la sitúa bajo sospecha, ante ese arte que reduce lo hermoso a un producto burgués, es fácil que el lector, o el espectador, se refugien de nuevo en lo que les aparece como una promesa de vivencias más satisfactorias. El problema es que cuando esa 
dirección se obtiene puramente por reacción da a menudo en el idilio gratuito, en el "buenismo", esto es, en el escamoteo del drama de la vida humana, en la elusión anticipada de todo conflicto. Por supuesto, esta tentación suele ir acompañada de la numantina, en una versión gazmoña de la tribalidad. Pero lo sustancial suyo, lo definitorio, no es tanto el sucedáneo de la comunión en la literatura o el arte romos, adocenados, lastrados por el cliché, sino una actitud ética que en lugar de enfrentarse a las incógnitas de la existencia cierra filas en torno a una visión unilateral y monolítica. Es decir, lo baña todo en una luz idílica y cancela de antemano toda experiencia estética real. Valgan como ejemplo los lectores que rechazan una novela como La leyenda del santo bebedor, de Joseph Roth, donde el héroe, ciertamente imperfecto, no obstante persevera en su misión en lugar de rebajar sus exigencias morales hasta hacerlas concordar con su comportamiento. Entre otras lecciones, $L a$ leyenda nos muestra el conflicto de un personaje que no ciega el pozo de la verdad, que acepta vivir en esa contradicción entre el ser y el deber ser, y que en esa medida permite que subsista este último, y por lo tanto permanezca un atisbo de esperanza.

Por eso cuando un alumno alega que rechaza esta novela por razones morales entiendo que yo he perdido la mía, por lo que a él respecta: la tentación buenista imposibilita la literatura porque ésta requiere del conflicto, de la presencia del mal; no se puede contar que todo empezó bien, continuó bien y terminó bien. El bien se percibe como tal, fundamentalmente, por contraste con el mal, que por tanto ha de manifestarse; o, al menos, por contraste con la amenaza de la pérdida del bien, con su fragilidad, con su inminente extinción. $Y$, por otra parte, si es preciso rechazar una novela porque su 
protagonista es un alcohólico, como argumentan algunos alumnos ante $\mathrm{La}$ leyenda, entonces habría que rechazar todos los libros donde aparece la desobediencia a Dios, el asesinato, el parricidio, el adulterio, la embriaguez, las conspiraciones políticas, la envidia, etc., hasta desembocar en el deicidio. Como la Biblia, por ejemplo. De nuevo, la tentación buenista, contra la que ya nos alertaba Baudelaire, no sólo impide que haya una experiencia estética rica y auténtica: con su escapismo flagrante, con su destrucción del puente entre el arte y la realidad cotidiana, impide que haya después esa especie de "conversión al fantasma”, ese regreso al mundo de la vida, que debe culminar esa experiencia. La pseudocultura buenista, una enésima forma de alienación, se parece a ese fósforo que sólo caldea una porción mínima de la atmósfera durante un instante, pero nunca logrará dejar tras de sí un rescoldo que permita caldear la habitación para una larga noche de invierno.

Una cuarta y última tentación es la gnóstica o esotérica. A menudo, la de autores y lectores que han seguido ejemplos como el de Simone Weil y los "cristianos sin Iglesia". Se trata, desde luego, de un camino mucho más rico y atractivo que los anteriormente enumerados, y que puede dar muchos frutos. Desde luego, incluye propuestas estéticamente más satisfactorias. Y, por supuesto, supone una senda espiritual y estética disponible para todas aquellas personas que viven fuera del judeocristianismo y de la Iglesia. Incluso, en muchos sentidos, para aquellos que ya están dentro de ella, en la medida en que testimonios como el de Weil y muchos más nos recuerdan que el espíritu sopla donde quiere y que Cristo no mira con mucha simpatía a los escribas y los fariseos (y que, por consiguiente, uno siempre debe preguntarse si no se está convirtiendo en uno de ellos). 
El peligro de esa tentación es que hace oídos sordos a todo cuanto no forme parte de la experiencia inmediata del sujeto. Es decir, que ha descartado la adhesión a un testigo y, por consiguiente, la fe. Su propósito, se comprueba a menudo cuando insiste en descubrir mediterráneos, es como el de Rilke "vivir en las preguntas". Lo cual significa que el autor esotérico se encuentra tan cómodo en ellas que no aspira a responderlas. Su búsqueda se ha vuelto intransitiva, circular. Carece en realidad de objeto. Su única salida se encontraría, en último término, en el salto pascaliano que rompería ese círculo al que él se aferra. Y, debo decirlo, en ocasiones esa búsqueda tiene lugar desde una pose de elitismo, de exhibición de la naturaleza minoritaria de su trayecto, de ostensión de su rechazo de todo lo institucional, hasta un punto de narcisismo donde toda pregunta por la Verdad ha quedado rechazada de antemano. Lo peor que le podría suceder a este buscador es darse de bruces con el hallazgo.

Imagino que este, el último párrafo de mi escrito, sería el lugar donde volcar mi propuesta ante semejante estado de cosas. Eso se espera en principio de un autor, de un texto. $\mathrm{Y}$, sin embargo, ante la complejidad arriba descrita sólo puedo elevar un puñado de convicciones íntimas, carentes de voluntad imperialista alguna. Fundamentalmente, aventuraré dos. La primera, en un extremo, que si el cristiano quiere ser "la sal de la tierra" ha de recordar que la sal no constituye "otro" alimento, sino un condimento: no se encuentra "frente a" la comida sino que se reparte sobre ella y la sazona. La segunda, en el extremo contrario, que en su elusión de la tentación numantina y monástica el autor judeocristiano puede juzgar tan conveniente como legítimo utilizar los medios que la tecnología le ofrece hoy para divulgar sus produc- 
tos, pero debe meditar si no carece de sentido permanecer provisionalmente en las catacumbas. Con la advertencia, claro está, de que vivir en las catacumbas implica aspirar a salir de ellas, mantener vivo el rescoldo de un fuego del que hoy tal vez participan pocos, pero cuyos beneficiarios últimos no han nacido aún. Quizá, ante el estruendo abrumador del akelarre, la verdad de la liturgia sólo puede susurrarse.

\section{Bibliografia empleada}

G. Agamben, Homo sacer, Trad. Antonio Gimeno, Valencia, Pre-Textos, 1998.

Ch. Baudelaire, Poèmes, París, Hachette, 1950.

S. T. Coleridge, Biographia Literaria, Trad. Gabriel Insausti, Valencia, Pre-Textos, 2012.

Th. de Quincey, Del asesinato considerado como una de las bellas artes. Trad. Luis Loayza. Barcelona: Bruguera, 1981.

F. Dostoievski, Crimen y castigo, Trad. José Fernández, Barcelona, Juventud, 1964.

F. Inciarte, Cultura y verdad, Pamplona, EUNSA, 2016.

J. Joyce, Retrato del artista adolescente, Trad. Dámaso Alonso, Madrid, Alianza, 1978.

J.-L. Kerner, "The Abject Art and Art History", Res, no 31, primavera 1997.

J. Kristeva, Poderes de la perversión, Buenos Aires, Siglo XXI, 1980.

F. Nietzsche, On the Genealogy of Morality, Trad. Carol Diethe, Cambridge, Cambridge University Press, 1997.

J.-P., Sartre, Baudelaire, Buenos Aires, Losada, 1957.

F. Truffaut, El cine según Hitchcock, Trad. Ramón G. Redondo, Madrid, Alianza, 1966.

Gabriel Insausti

ginsausti@unav.es 